\title{
"Add Flow to the Fire": Flow and Hope as a Shield against Burnout of Fire Service Workers
}

\section{Vasiliki Yotsidi1 ${ }^{*}$, Ntina Kourmousi², Eirini Dermitzaki ${ }^{3}$, Christos Pezirkianidis ${ }^{4}$, Kalliope Kounenou ${ }^{2}$}

\author{
${ }^{1}$ Psychiatric Clinic, Medical School, National and Kapodistrian University of Athens, Athens, Greece \\ ${ }^{2}$ Department of Education, School of Pedagogical \& Technological Education (ASPETE), Athens, Greece \\ ${ }^{3}$ Hellenic Fire Service Headquarters, Athens, Greece \\ ${ }^{4}$ Panteion University of Social and Political Sciences, Athens Greece \\ Email: vickyyotsidi@netscape.net
}

How to cite this paper: Yotsidi, V., Kourmousi, N., Dermitzaki, E., Pezirkianidis, C. and Kounenou, K. (2018). "Add Flow to the Fire": Flow and Hope as a Shield against Burnout of Fire Service Workers. Psychology, 9, 1291-1305. https://doi.org/10.4236/psych.2018.96079

Received: May 8, 2018

Accepted: June 24, 2018

Published: June 27, 2018

Copyright $\odot 2018$ by authors and Scientific Research Publishing Inc. This work is licensed under the Creative Commons Attribution International License (CC BY 4.0).

http://creativecommons.org/licenses/by/4.0/

\begin{abstract}
Being related to optimal functioning, the concept of flow is valuable for a variety of tasks and activities that entails human endeavor. Though flow gives the individuals the ability to focus energetically and direct their resources towards their goals, it was not studied in relation to the goal-directed variable of hope to date. The present study aimed to examine flow, hope and burnout in professional firefighters in Greece and to examine the antecedents of flow and hope after a challenging work incident. The Dispositional Flow Scale-2 (DFS-2), the Maslach Burnout Inventory-General Survey (MBI-GS) and the Adult Dispositional Hope Scale (ADHS) were filled in by 180 firefighters in a pre- and post-study design. The results showed that after a fire incident, firemen's burnout scores increased, whereas hope scores decreased. Flow and hope were positively related to professional efficacy, while stable pathways of the ADHS were associated with increased flow after the fire incident. Significant differences were detected in both flow and hope levels in relation to the participants' burn out, as well as their age, educational level, and family status. The findings have important practical and research implications in terms of empowering workers at such stressful and demanding professions of high social and public health importance.
\end{abstract}

\section{Keywords}

Flow, Hope, Burnout, Firefighters, Positive Psychology, Occupational Health

\section{Introduction}

Since its conception in the field of Positive Psychology by Mihaly Csikszentmi- 
halyi (1975/2000), flow has emerged as a multifaceted, process-laden phenomenon, making its empirical examination an ever-constant research challenge in the social and work environments. Flow describes a subjective mental state in which someone is fully focused and energized, combined with having the adequate skills, during a condition of high challenge (Csikszentmihalyi, 2014; Csikszentmihalyi \& LeFevre, 1989; Nakamura \& Csikszentmihalyi, 2014). Particularly, the prerequisites for entering flow include a combination of high enough opportunities for action and high capabilities to pursue goals (Nakamura \& Csikszentmihalyi, 2009, 2014), a situation that enables someone to feel immersed with the task and totally engaged in the here-and-now course of how things turn to be. Such a peak experience is achieved when challenges are optimally balanced with skills, while both challenges and skills should be greater than a weekly average (Moneta, 2012). An alternative prominent conception of flow is "being in the zone", which depicts one's complete absorption as well as satisfaction in the very present activity, a process that gradually leads to an increased rewarding effect (Nakamura \& Csikszentmihalyi, 2009, 2014). Along with absorption and enjoyment as the two main flow elements, being driven by an intrinsic motivation pertains as the third component of flow (Csikszentmihalyi, 1997). These three components have been found by flow-researchers to be a common ground in the studies regarding performance and overall productivity and creativity in several fields (Bakker, 2005; Moneta, 2012).

To date, flow research has been conducted in relation to work (Ceja \& Navarro, 2011; Csikszentmihalyi \& LeFevre, 1989; Moneta, 2012), sports (Jackson \& Csikszentmihalyi, 1999; Jackson \& Eklund, 2002; Kawabata, Mallett, \& Jackson, 2008), arts (Bakker, 2005; Csikszentmihalyi \& LeFevre, 1989), and online activities and gaming (Choi, Kim, \& Kim, 2007; Wan, \& Chiou, 2006; Wang, Liu, \& Khoo, 2009). Regarding the workplace, the scholars applied the concept of flow in terms of personal and organizational goal alignment, while a "positive organizational behavior" was found to be associated with positive psychological resources, such as confidence, hope, optimism, and resilience (Luthans, Luthans, \& Luthans, 2004). In line with the previous evidence that flow is related to well-being, Sartori \& DelleFave (2014) examined the role of flow in a highly challenging situation such as the rescuing experience of professionals and volunteers of the Italian Red Cross. In their study, working as a first-aid responder to emergency situations was found to be a rewarding optimal experience, thus promoting personal well-being. Despite previous studies establishing the beneficial role of flow for individual performance and well-being, there is a relative dearth of empirical research on how the flow is related to other goal-directed variables, especially in work situations that demand high levels of concentration and efficacy. To fill the existing gaps in the literature, the present study sought to examine the relationship of flow with hope and burnout in firefighters, a highly emergency and potentially life-threatening, experience that is rarely investigated to date.

Being a fireman is a highly stressful work since it requires both physical vigil- 
ance and mental strength to perform high-risk tasks, to save human lives and protect oneself from greater danger (Riolli \& Savicki, 2012; Tuckey \& Hayward, 2011). Considering the many work hours, the rotating shifts, the unexpected and often demanding incidents, or even the casualties they have to face, it is not surprising that firemen frequently report high levels of burnout (Halbesleben, Osburn, \& Mumford, 2006; Lourel, Abdellaoui, Chevaleyre, Paltrier, \& Gana, 2008; Mitani, Fujita, Nakata, \& Shirakawa, 2006; Smith, Hughes, DeJoy, \& Dyal, 2018).

Burnout has been defined as a response to long-term work stress and has been theorized that it contains three components: emotional exhaustion, depersonalization in the form of cynicism and lower levels of professional self-efficacy (Maslach, Schaufeli, \& Leiter, 2001). Additionally, it refers to a person's cynical view of his or her occupation, including one's doubts on one's ability to perform efficiently (Maslach, Jackson, \& Leiter, 1996). Since firefighters are among the first responders in case of fire, extrication after massive natural disasters or traffic accidents, it has been well established that they may exhibit signs of fatigue, exhaustion, even changes in sleep patterns (Lourel, Abdellaoui, Chevaleyre, Paltrier, \& Gana, 2008; Mitani, Fujita, Nakata, \& Shirakawa, 2006; Smith, Hughes, DeJoy, \& Dyal, 2018). Burnout in firemen may also manifest in psychological and social ways, such as alienation, compassion fatigue, doubting one's professional identity, work stress, fighting with family members and being prone to accidents during work (Huynh, Xanthopoulou, \& Winefield, 2013; Katsavouni, Bebetsos, Malliou, \& Beneka, 2015; Smith, DeJoy, Dyal, \& Huang, 2017).

Hope, on the other hand, a concept that also pertains to the field of Positive Psychology (Snyder, Rand, \& Sigmon, 2002), refers to a positive motivational state that drives people towards goal achievement, since it was found to be associated with optimism, self-efficacy and goal-oriented behaviors (Peterson \& Byron, 2008; Snyder et al., 2002). According to Snyder's cognitive model (Snyder, 2002; Snyder et al., 1991), a hopeful individual is capable to create paths in order to achieve goals (pathways) and motivate oneself mentally to follow those pathways (agency). Findings from a recent integrative review (Yotsidi, Pagoulatou, Kyriazos, \& Stalikas, 2018) showed that hope at the workplace was associated with employees' perceived motivations for pursuing their goals and their ability for task accomplishment, while it also played a predictive role in employees' self-efficacy, job satisfaction and overall well-being in different professions and work environments. For example, more hopeful employees had higher job performance and provided a wider array of solutions to difficulties encountered at the workplace (Peterson \& Byron, 2008). On the contrary, the existing evidence regarding firemen showed that hopelessness was associated to high stress (Steffen \& Smith, 2013) and psychological maladjustment (Riolli \& Savicki, 2012), while it influenced the firefighters' well-being and ability to cope with traumatic events. Taking into account the relative dearth of evidence on the role of hope in coping with stress and achieving positive outcomes at demanding working conditions, there is room for further empirical research.

In view of the previous findings that hope and flow are both goal-directed va- 
riables that promote optimum functioning at work, the current study builds on the existing literature by examining the link between hope and flow in relation to the firemen's burnout. To our best knowledge, this is the first time that these two positive variables are assessed conjointly in relation to burnout in such a stressful profession. Particularly, we hypothesized that: 1) Burnout would be negatively related to firemen's hope levels, 2) burnout and hope levels would be modified after a fire incident compared to prior the incident (i.e. at an ordinary working day), 3) demographic and work-related variables may be associated with burnout and hope, and 4) firemen's flow and hope at a fire extinguishing incident would be predicted by their burnout levels and individual characteristics. Understanding in more detail the mechanisms that underlie the development of flow in relation to hope and burnout in a profession of high exposure to challenging situations and of high social importance is expected to empower professionals and improve the provided services.

\section{Method}

\subsection{Sample}

Our sample consisted of 180 firefighters (175 men and 5 women) who worked at the central body of the Hellenic Fire Service located in Athens. Seventy-five of them (41.9\%) were between 25 to 34 years old, seventy-nine (44.1\%) between 35 to 44 years and few (14\%) were older than 45 years. Almost half $(51.4 \%)$ were married and most of the participants (64.6\%) were high school graduates. The majority of the firemen had previous service for less than ten years (67.2\%) and held a permanent position in the fire force (80.7\%). Most of the participants were firefighters (60.9\%), but officers and sub officers were also included. Sample characteristics are presented in detail in Table 1.

\subsection{Measures}

Maslach Burnout Inventory-General Survey-MBI-GS. The MBI-GS was developed as an alternative form of the original MBI to measure burnout as an occupational issue and as a crisis in one's involvement with work for different occupational groups other than human service providers (Maslach, Jackson, \& Leiter, 1996). It includes 16 items that measure one's relationship with their work on a continuum, from engagement to burnout, and produces three subscales, parallel to those of the original MBI: Exhaustion, Cynicism, and Professional Efficacy. Exhaustion refers to both emotional and physical fatigue (e.g. "Working all day is really a strain for me"). Cynicism refers to indifference or distance towards work, that is a dysfunctional coping (e.g. "I don't really care if my work is done well or poorly"), while Professional Efficacy refers to satisfaction with one's work accomplishments and to a person's expectations of his or her work effectiveness (e.g. "At my work, I am confident that I am effective at getting things done"). All items are rated on a 7 -point scale $(0=$ never, $6=$ everyday $)$. High scores on Exhaustion and Cynicism and low scores on Professional Efficacy 
Table 1. Sample characteristics.

\begin{tabular}{cccc}
\hline & $\mathrm{N}(\%)$ & $\mathrm{N}(\%)$ \\
\hline Sex & & Educational status & \\
Women & $175(97.2)$ & High school graduate & $115(64.6)$ \\
Age (years) & $5(2.8)$ & College graduate & $15(8.4)$ \\
$25-34$ & & University graduate & $41(23)$ \\
$35-44$ & $75(41.9)$ & Post graduate degree & $7(3.9)$ \\
$45-54$ & $24(13.4)$ & Job status & \\
$55-64$ & $1(0.6)$ & Permanent & $142(80.7)$ \\
Family status & 5-year contract & $34(19.3)$ \\
Unmarried & $82(45.8)$ & Rank structure & $106(60.9)$ \\
Married & $92(51.4)$ & Firefighter & $38(21.8)$ \\
Divorced & $4(2.2)$ & Fire officer & $30(17.2)$ \\
Widowed & $1(0.6)$ & Fire sub officer & \\
Number of children & & & $121(67.2)$ \\
None & $99(55.3)$ & Years of service & $48(26.7)$ \\
1 - 2 & $71(39.7)$ & $0-10$ & $11(6.1)$ \\
At least 3 & $9(5.0)$ & $11-20$ &
\end{tabular}

reflect higher levels of burnout.

Adult Dispositional Hope Scale-ADHS. In order to measure the participants' level of hope, the Greek version (Moustaki \& Stalikas, 2012) of the ADHS (Snyder, 2002; Snyder et al., 1991) was used. The 8 items of the ADHS are divided equally into two subscales: 1) Agency, which refers to successful goal-directed determination (e.g. "I meet the goals that I set for myself") and 2) Pathways, which refer to the available plans to accomplish goals (e.g., "There are lots of ways around any problem"). It is rated on a 4-point Likert scale ranging from 1 = Definitely False to $4=$ Definitely True and a total score can be computed with higher scores reflecting higher levels of hope.

Dispositional Flow Scale-2-DFS-2. The Dispositional Flow Scale-2 (Jackson \& Eklund, 2004) was used to assess the frequency with which firemen experience flow after a challenging work incident. It consists of 36 items and produces 9 subscales (4 items each) that correspond to Csikszentmihalyi's nine-dimensional flow model: challenge-skill balance (e.g., "I am challenged but I believe my skills will allow me to meet the challenge"), action-awareness merging (e.g., "I perform automatically, without thinking too much"), clear goals (e.g., "I know what I want to achieve"), unambiguous feedback (e.g., "It is really clear to me how my performance is going"), total concentration (e.g., "I am completely focused on the task at hand"), sense of control (e.g., "I have a sense of control over what I am doing"), loss of self-consciousness (e.g., "I am not concerned with what others may be thinking of me"), a transformation of time (e.g., "I lose my normal 
awareness of time"), and autotelic experience (e.g., "The experience is extremely rewarding"). The participants responded on a 5-point Likert scale, ranging from $1=$ never to $5=$ always. The total score of all 36 items represents the score of flow disposition, with higher scores reflecting higher levels of flow in the activity studied.

All the aforementioned measures and their subscales had adequate Cronbach's alpha that exceeded the minimum reliability standard of 0.70 .

Demographic data. Participants reported on their age, sex, educational and marital status, the number of their children, as well as on work-related information, such as permanency, their rank and the years of service on the fire force.

\subsection{Procedure \& Statistical Analysis}

The present study took place in the wider region of Attika in Greece, where the capital is located and half of the population of the country lives. Formal approval was granted by the Hellenic Fire Service Headquarters prior to the study. Information on the purpose of the study was given and clarifications were provided, when necessary. Firefighters who participated in the study provided an informed consent and completed the measures individually in the fire department that they worked. Questionnaires were filled in two different time points: first, at an ordinary, uneventful day, during a shift at the fire department, and then, after the participants' involvement in a fire extinguishing incident. The MBI-GS and the ADHS were administered in both measurements to acquire pre- and postcomparative data, while the DFS- 2 was added in the second measurement to assess the firefighters' flow levels during their exposure to a highly challenging situation. In the second phase of data collection, participants were asked to fill in the questionnaires once they returned to the fire department. Anonymity and confidentiality of the data were ensured, while participants received no incentives to participate in the study.

With regard to the statistical analysis of the data, continuous variables are presented with the mean and standard deviation (SD). Quantitative variables are presented with absolute and relative frequencies. Pearson's correlations coefficients were used to explore the association of two continuous variables. Differences in changes in the study variables during the follow-up period between different groups were evaluated using repeated measurements analysis of variance (ANOVA). Multiple linear regression analysis in a stepwise method ( $p$ for removal was set at 0.1 and $p$ for entry was set at 0.05 ) was conducted in order to identify independently associated parameters with Flow and total Hope score after a fire event. Adjusted regression coefficients $(\beta)$ with standard errors ( $S E$ ) were computed from the results of the linear regression analyses. All $p$ values reported are two-tailed. Statistical significance was set at 0.05 and analyses were conducted using SPSS statistical software (version 22.0).

\section{Results}

As shown in Table 2, all the Hope subscales before and after the fire extinguishing 
Table 2. Hope and burnout correlations at baseline, after a fire incident, and their changes.

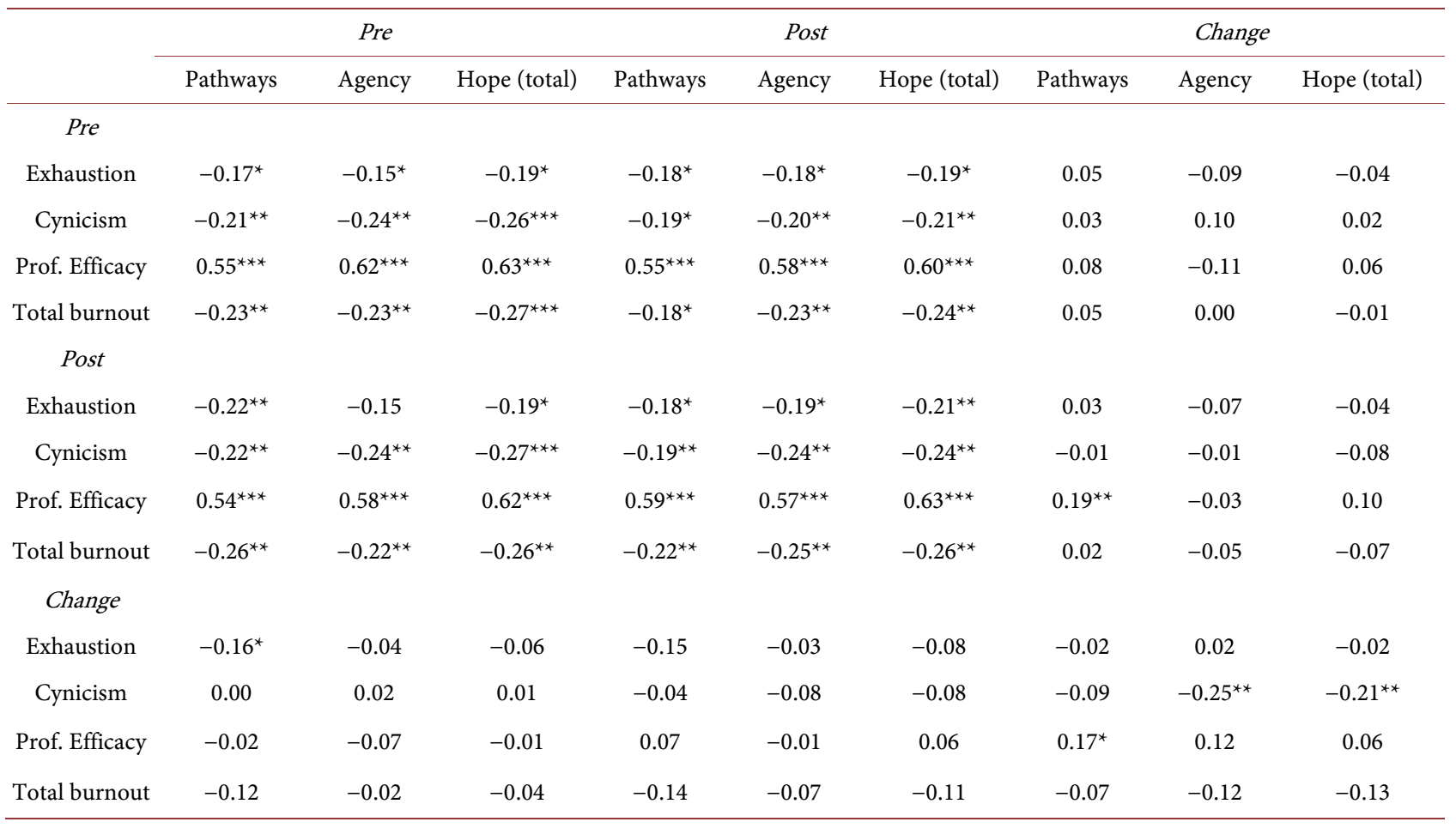

Note. ${ }^{\star} p<0.05,{ }^{* *} p<0.01,{ }^{* * *} p<0.001$.

incident were associated with the Burnout subscales at baseline and after the incident, with the exception of the Exhaustion at the post-measurement with the Agency at the baseline measure, indicating a link between burnout and hope. Particularly, both the pre- and post-fire incident scores of Pathways, Agency and total Hope were significantly associated with pre- and post-scores of Exhaustion, Cynicism, Professional Efficacy and total Burn out. The highest correlations were observed between Professional Efficacy and all the ADHS subscales. Changes in Pathways were found to be associated with Professional Efficacy after the work-related incident $(r=0.19, p<0.01)$. Furthermore, changes in the Agency and the total Hope scores were significantly associated with the changes in the Cynicism subscale $(r=-0.25, p<0.01$ and $r=-0.21, p<0.01$ respectively), while changes in the Pathways were associated with changes in the Professional Efficacy subscale $(r=0.17, p<0.05)$, showing that changes in burn out were correlated with perspective changes in hope.

Significant differences were found in the firemen's Burnout and Hope levels after being involved in a challenging work incident compared to their prior state (Table 3). Particularly, significantly greater levels in the Exhaustion and the total MBI-GS score were found after the incident $[t(164)=5.75, p<0.001$ and $t(164)=$ $5.27, p<0.001$ respectively], indicating the negative effect of the fire extinguishing event on the fire workers' burn-out levels. In contrast, the score on the Pathways subscale of the ADHS was decreased significantly $[t(163)=-2.77, p<$ 0.01 ] 
Table 3. Differences in Burnout and Hope subscales before and after a fire incident.

\begin{tabular}{cccccc}
\hline & Pre & Post & Change & \multirow{2}{*}{$\mathrm{t}$} & $\mathrm{df}$ \\
\cline { 2 - 5 } & Mean $(\mathrm{SD})$ & Mean $(\mathrm{SD})$ & Mean $(\mathrm{SD})$ & & \\
\hline Exhaustion $(\mathrm{a}=0.91)$ & $1.76(1.24)$ & $2.12(1.45)$ & $0.36(0.73)$ & $5.75^{* * *}$ & 164 \\
Cynicism $(\mathrm{a}=0.72)$ & $1.66(1.09)$ & $1.73(1.06)$ & $0.07(0.51)$ & 1.39 & 164 \\
Professional efficacy $(\mathrm{a}=0.80)$ & $4.98(0.93)$ & $4.92(0.94)$ & $-0.06(0.61)$ & -0.88 & 164 \\
Total burn-out $(\mathrm{a}=0.71)$ & $1.71(0.98)$ & $1.92(1.07)$ & $0.21(0.46)$ & $5.27^{* * *}$ & 164 \\
Pathways $(\mathrm{a}=0.81)$ & $16.59(3.00)$ & $16.22(3.25)$ & $-0.37(1.66)$ & $-2.77^{* *}$ & 163 \\
Agency $(\mathrm{a}=0.82)$ & $16.46(3.03)$ & $16.44(2.99)$ & $-0.02(1.27)$ & -0.12 & 163 \\
Hope (total score $)(\mathrm{a}=0.89)$ & $33.16(5.47)$ & $32.97(5.62)$ & $-0.19(2.04)$ & -1.69 & 155 \\
\hline
\end{tabular}

Note. ${ }^{*} p<0.05,{ }^{* *} p<0.01,{ }^{* * *} p<0.001$.

Demographic and occupational data were examined to assess whether they contributed to the changes in Burnout and Hope subscales before and after a fire event (Table 4). Interestingly, Exhaustion was found to have a greater increase in more educated participants $[F(1,161)=5.02, p<0.05]$. On the other hand, Cynicism was found to be increased significantly only in high school graduate participants and not in those with a higher educational level $[F(1,161)=6.04, p<$ 0.05]. Additionally, Pathways had a greater decrease after the incident in the married participants $[F(1,161)=4.71, p<0.05]$, and those that had children $[F$ $(1,161)=4.34, p<0.05]$.

Flow dimension after a fire event was found to be significantly correlated with the levels of Professional Efficacy $(r=0.61, p<0.001)$, Pathways, $(r=0.54, p<$ $0.001)$, Agency, $(r=0.61, p<0.001)$ and total Hope score $(r=0.64, p<0.001)$, as measured before the event (Table 5). Similarly, flow dimension after a fire event was found to be significantly correlated with levels of Professional Efficacy ( $r=$ $0.61, p<0.001)$, Pathways $(r=0.62, p<0.001)$, Agency $(r=0.63, p<0.001)$ and total Hope score $(r=0.66, p<0.001)$ as measured after the fire event. Also, changes in Pathways subscale were found to be significantly correlated with Flow $(r=0.24, p<0.001)$, indicating that lower changes in Pathways are associated with greater levels of Flow.

In order to examine the main hypothesis of our study, stepwise multiple regression analysis was conducted with the Flow as the dependent variable and all the demographic and work-related characteristics, MBI-GS and ADHS subscales before the incident, as independent variables (Table 6). According to the findings, increased levels of both Professional Efficacy and Pathways were associated with greater levels of Flow $(\beta=0.18, p<0.001$ and $\beta=0.05, p<0.001$, respectively). Also, the Flow score was higher for firemen aged between 45 to 64 years old in comparison to their colleagues aged less than 34 years $(\beta=0.19, p<0.05)$.

Furthermore, stepwise multiple regression analysis with the Hope total score after the work-related incident as the dependent variable and all the demographic and work-related data and the MBI-GS subscales before the incident as independent variables, showed that increased Cynicism was associated with 
Table 4. Significant correlations of demographic variables with the changes in Burnout and Hope before and after a fire incident.

\begin{tabular}{|c|c|c|c|c|c|}
\hline & Pre & Post & Change & & \\
\hline & Mean (SD) & Mean (SD) & Mean (SD) & $\mathrm{t}^{\mathrm{b}}(\mathrm{df})$ & $\mathrm{F}^{\mathrm{c}}(1,161)$ \\
\hline \multicolumn{6}{|l|}{ Exhaustion } \\
\hline \multicolumn{6}{|l|}{ Educational status } \\
\hline High school graduate & $1.73(1.22)$ & $1.96(1.41)$ & $0.24(0.63)$ & $3.80^{\star \star \star}(104)$ & $5.02^{*}$ \\
\hline College/University graduate-Postgraduate degree & $1.83(1.31)$ & $2.39(1.51)$ & $0.56(0.87)$ & $4.36^{* \star \star}(57)$ & \\
\hline$t^{a}(d f)$ & $0.52(175)$ & $1.81(161)$ & & & \\
\hline \multicolumn{6}{|l|}{ Cynicism } \\
\hline \multicolumn{6}{|l|}{ Educational status } \\
\hline High school graduate & $1.72(1.09)$ & $1.85(1.06)$ & $0.12(0.55)$ & $2.40^{*}(104)$ & $6.04^{*}$ \\
\hline College/University graduate-Postgraduate degree & $1.56(1.09)$ & $1.52(1.05)$ & $-0.05(0.42)$ & $-1.37(57)$ & \\
\hline$t^{a}(d f)$ & $0.94(175)$ & $1.91(161)$ & & & \\
\hline \multicolumn{6}{|l|}{ Pathways } \\
\hline \multicolumn{6}{|l|}{ Married } \\
\hline No & $16.45(2.90)$ & $16.26(3.04)$ & $-0.19(1.44)$ & $-0.46(80)$ & $4.71^{*}$ \\
\hline Yes & $16.76(3.09)$ & $16.11(3.48)$ & $-0.65(1.82)$ & $-3.15^{\star \star}(81)$ & \\
\hline$t^{a}(d f)$ & $0.68(175)$ & $0.29(161)$ & & & \\
\hline \multicolumn{6}{|l|}{ Having children } \\
\hline No & $16.48(2.9)$ & $16.23(3.1)$ & $-0.25(1.4)$ & $-0.82(91)$ & $4.34^{*}$ \\
\hline Yes & $16.77(3.12)$ & $16.13(3.47)$ & $-0.65(1.93)$ & $-2.90^{\star \star}(70)$ & \\
\hline $\mathrm{t}^{\mathrm{a}}(\mathrm{df})$ & $0.65(175)$ & $0.20(161)$ & & & \\
\hline
\end{tabular}

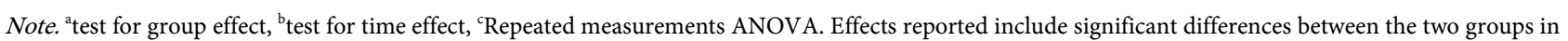
the degree of change in each particular variable during the study period. ${ }^{*} p<0.05,{ }^{* *} p<0.01,{ }^{* *} p<0.001$.

Table 5. Correlations of Flow after a fire incident with Burnout and Hope subscales at baseline, after the incident and their perspective changes.

\begin{tabular}{|c|c|c|c|}
\hline & \multicolumn{3}{|c|}{ Flow (post) } \\
\hline & Pre & Post & Change \\
\hline Exhaustion & -0.07 & -0.09 & -0.01 \\
\hline Cynicism & -0.13 & -0.18 & -0.15 \\
\hline Professional Efficacy & $0.61^{* * *}$ & $0.61^{* * *}$ & -0.03 \\
\hline Total Burn-out & -0.12 & -0.15 & -0.09 \\
\hline Pathways & $0.54^{* * *}$ & $0.62^{* * *}$ & $0.24^{* *}$ \\
\hline Agency & $0.61^{* * *}$ & $0.63^{* * *}$ & -0.01 \\
\hline Hope (totalscore) & $0.64^{* * *}$ & $0.66^{* * *}$ & $0.17^{*}$ \\
\hline
\end{tabular}

Note. ${ }^{\star} p<0.05,{ }^{* *} p<0.01,{ }^{* * *} p<0.001$.

lower levels of Hope ( $\beta=-0.68, p<0.05$ ), while increased Professional Efficacy was associated with greater levels of Hope $(\beta=3.35, p<0.001)$. Finally, lower levels of total Hope were found again in the more educated firemen $(\beta=-2.82, p<$ 0.001). 
Table 6. Stepwise multiple regression analysis for flow and hope after a fire incident.

\begin{tabular}{|c|c|c|c|}
\hline & $B$ & $S E B$ & $\beta$ \\
\hline \multicolumn{4}{|l|}{ Flow (post) } \\
\hline Prof. Efficacy (pre) & $0.18^{\star * *}$ & 0.03 & 0.38 \\
\hline Pathways (pre) & $0.05^{\star * *}$ & 0.01 & 0.37 \\
\hline \multicolumn{4}{|l|}{ Age (years) } \\
\hline \multicolumn{4}{|l|}{$25-34$ (ref.) } \\
\hline $35-44$ & 0.05 & 0.05 & 0.06 \\
\hline $45-64$ & $0.19^{*}$ & 0.08 & 0.15 \\
\hline $\mathrm{R}^{2}$ & & 0.46 & \\
\hline $\mathrm{F}(4,163)$ & & $37.30^{* * *}$ & \\
\hline \multicolumn{4}{|l|}{ Hope (totalscore) (post) } \\
\hline Cynicism (pre) & $-0.68^{\star}$ & 0.32 & -0.13 \\
\hline Prof. Efficacy (pre) & $3.35^{\star * *}$ & 0.38 & 0.55 \\
\hline \multicolumn{4}{|l|}{ Educational status } \\
\hline \multicolumn{4}{|l|}{ High schoolgraduate (ref.) } \\
\hline College/University graduate - Postgraduate degree & $-2.82^{* * *}$ & 0.73 & -0.24 \\
\hline $\mathrm{R}^{2}$ & & 0.42 & \\
\hline $\mathrm{F}(3,151)$ & & $38.34^{* * *}$ & \\
\hline
\end{tabular}

Note. ${ }^{\star} p<0.05,{ }^{* *} p<0.01,{ }^{* * *} p<0.001$.

Conclusively, firefighters' burn out was found to be related to their levels of hope both prior and after a fire incident. A fire incident generated changes in the participants' burn out and hope, since firefighters' hope pathways showed a considerable decrease, while at the same time, their levels of exhaustion and overall burnout were increased. Specific demographic data, such as the educational level and the marital status, were found to have an effect on the changes that occurred after a fire incident. Noteworthy, the participants' flow after a fire incident was affected from the increased levels of participants' professional efficacy and hope pathways, and it was also associated with their age. Additionally, hope after the fire incident could be predicted from the firemen's burn out before the incident and their educational status.

\section{Discussion}

The aim of the present study was to investigate flow and hope in firefighters, a professional group that is exposed to high stress and burnout due to the demanding, risky and often life-threatening nature of the duty tasks. Flow represents a peak experience that gives the individuals the ability to focus, act energetically and direct all their resources towards their goals Csikszentmihalyi (1975/2000). Similarly, hope helps people to channel their motivations to the best alternative pathways and to become more decisive and effective (Snyder, 1994; Yotsidi et al., 2018). As such, it was considered that by understanding the role of flow and hope as potential buffers against the work challenges, this would 
provide novel perspectives on how firefighters might be better armored against the risks of their work as well as be more adequately equipped to deal with its everyday hazards.

As it might have been expected, the fire service workers' hope was found to relate significantly to their burn out levels, at both times of the study, prior and after the fire incident. In particular, hope was positively associated with professional efficacy, lending support to previous findings that hopeful individuals are motivated and able to achieve their goals at work (Peterson \& Byron, 2008). In contrast, exhaustion, cynicism and the total burnout score were negatively associated with hope, a finding that highlights the link between hopelessness and poor mental health (Riolli \& Savicki, 2012; Steffen \& Smith, 2013). Similarly, flow, as it was measured after the fire incident, was positively related to the firemen's professional efficacy and hope levels, assessed both prior and after the fire extinguishing event.

These findings are in keeping with the previous research that has demonstrated the positive impact of flow and hope in work and life experiences (Csikszentmihalyi, 1975/2000; Snyder et al., 2002). The present study builds on the existing literature by examining the link between flow and hope, and by providing greater detail into the importance of this relationship as a potential safeguard in challenging situations. Taking into account that "going with the flow" entails a challenge-skill balance, clear goals, a high focus and a sense of control, these findings shed light to the role of flow for enhancing work engagement, especially in activities of high stress. Noteworthy, greater levels of flow were found to be related to lower changes in firefighters' pathways, before and after the fire incident. That is, having a clear plan to meet goals prior to an arduous task and being stable to this planning while struggling with the difficulty, made firefighters be more concentrated on their duty. Further research into the relationship between flow and hope in different work environments and with a longitudinal perspective that would take into account the impact of this relationship to job performance is warranted.

Another telling finding of hope in fire service workers was that firefighters' hope pathways showed a considerable decrease after a critical work incident, such as a fire extinguishing event. At the same time, their levels of exhaustion and overall burnout were increased after putting out the fire. Exposure to intense trauma situations, such as a fire, a traffic accident or a natural disaster, seems to take a toll on firemen's feelings of exhaustion and fatigue, and make them feel inadequate or unable to envision and implement suitable solutions (Lourel et al., 2008; Mitani et al., 2006; Smith et al., 2017). The potential preventive role of enhancing fire service workers' flow along with their hope levels as a measure against anticipated burn out increases sets a fruitful avenue for further empirical research.

Future studies could also build on current findings by investigating whether specific demographic and work-related variables should be taken into account when interventions to prevent burn out are planned and evaluated. Our finding 
that the firemen with a university education reported an increase in exhaustion after the fire incident compared to high school graduates, while instead the latter reported an increase in cynicism, indicated that the participants' education may intervene in the different ways that burn out is experienced, since more educated professionals expressed a burn out syndrome in rather physical terms while high school graduates expressed it in more psychological terms. Furthermore, married participants and those with children showed a more significant decrease in pathways after the fire incident, compared to their unmarried colleagues and those with no children. The reason why the present findings are at odds with previous evidence that showed married people to report higher scores of hope (Bailey \& Snyder, 2007), might be the fact that having the responsibility of a family may have increased firemen's stress levels and feelings of debilitation, thus influencing more so their ability to plan paths for their goals when they encounter stressful or even traumatic events.

More importantly, it was found in our study that an increase in the flow after a fire incident could be predicted by increased levels of both professional efficacy and pathways before the incident, as well as by participants' older age. These findings are in keeping with a recent study (Sartori \& DelleFave, 2014) on emergency workers (including firefighters), which suggested that first-aid workers can achieve optimal experience during emergency circumstances as long as they are equipped with the necessary skills and personal emotional resources to cope with such demanding duties. With regard to the role of the participants' age, despite existing evidence that older individuals experience lower levels of hope (Bailey \& Snyder, 2007), our findings may be explained by the nature of the work that demand a high level of experience to build a sense of security and control by the fire service workers.

Another telling finding of our study was that hope after a work-related incident was predicted by lower levels of cynicism and higher levels of professional efficacy prior to the incident, while those firemen with an advanced educational level reported lower levels of hope. As might have been expected, a fireman with high levels of disengagement, who views work with a certain apathy and resign, tends to perceive work in an even more futile and hopeless way after a challenging incident (e.g., a casualty on the work may increase hopelessness). On the other hand, a fireman who feels that s/he has the skills to efficiently deal with the difficulties of the profession maintains his or hers hopeful stance even after the incident. These findings stress the importance of adequate training based on strengthening positive personal resources, such as hope and flow.

Nevertheless, a number of limitations need to be considered in the interpretation of the results. First, the participants in the study worked in a specific, mainly urban, district of the country, thus not being representative of a nationwide sample. Yet, they covered the region with the highest population density, while they were charged with providing their services across the country when needed. For reasons of homogeneity, the work-related incident that was examined in the 
pre- and post- study design was related to a fire extinguishing event, which is the most common duty of fire service workers. Further studies could investigate whether there might be differences in burn out, flow and hope levels on the basis of different types of fire service tasks (e.g., car accidents, rescues, earthquakes, etc.). Notwithstanding limitations, the results of the present study have a number of important implications.

\section{Conclusion}

The findings have important practical and research implications in terms of empowering workers at such stressful and demanding professions of high social and public health importance. Interventions in the fire force could focus on boosting the firefighters' professional efficacy since this was associated with their flow and hope. Having a sense of accomplishment in one's profession and being able to do the work efficiently prevails to be of high importance for the work engagement and the hopeful pursuit of goals. At the same time, incorporating hope agency and pathways into existing interventions for first-aid professionals may be beneficial for experiencing flow at work. Based on our findings, the firefighters who think that there are alternative ways to overcome difficulties may be in an advantageous position to focus on what is important, perform better and enjoy the process. Therefore, training programs to professional firefighters should aim at increasing their sense of hopefulness and flow, along with being tailor-made to professionals' needs on the basis of particular demographic characteristics that were found in the current study to play an important role. The development of such prevention-based training would provide firefighters with the coping skills to overcome job-related stressors and find fulfillment in their work. Overall, shedding light on the role of flow and hope in such a stressful profession is considered to expand the scope of their usefulness in areas of great social and public health interest.

\section{References}

Bailey, T. C., \& Snyder, C. R. (2007). Satisfaction with Life and Hope: A Look at Age and Marital Status. The Psychological Record, 57, 233-240. https://link.springer.com/article/10.1007/BF03395574 https://doi.org/10.1007/BF03395574

Bakker, A. B. (2005). Flow among Music Teachers and Their Students: The Crossover of Peak Experiences. Journal of Vocational Behavior, 66, 26-44. https://doi.org/10.1016/j.jvb.2003.11.001

Ceja, L., \& Navarro, J. (2011). Dynamic Patterns of Flow in the Workplace: Characterizing Within-Individual Variability Using a Complexity Science Approach. Journal of Organizational Behavior, 32, 627-651. https://doi.org/10.1002/job.747

Choi, D. H., Kim, J., \& Kim, S. H. (2007). ERP Training with a Web-Based Electronic Learning System: The Flow Theory Perspective. International Journal of Human-Computer Studies, 65, 223-243. https://doi.org/10.1016/j.ijhcs.2006.10.002

Csikszentmihalyi, M. (1975/2000). Beyond Boredom and Anxiety. San Francisco: Jossey-Bass. 
Csikszentmihalyi, M. (1997). Finding Flow: The Psychology of Engagement with Everyday Life. New York: HarperCollins.

Csikszentmihalyi, M. (2014). Toward a Psychology of Optimal Experience. In M. Csikszentmihalyi (Ed.), Flow and the Foundations of Positive Psychology (pp. 209-226), Dordrecht: Springer. https://doi.org/10.1007/978-94-017-9088-8_14

Csikszentmihalyi, M., \& LeFevre, J. (1989). Optimal Experience in Work and Leisure. Journal of Personality and Social Psychology, 56, 815-822. https://doi.org/10.1037/0022-3514.56.5.815

Halbesleben, J. R., Osburn, H. K., \& Mumford, M. D. (2006). Action Research as a Burnout Intervention: Reducing Burnout in the Federal Fire Service. The Journal of Applied Behavioral Science, 42, 244-266. https://doi.org/10.1177/0021886305285031

Huynh, J. Y., Xanthopoulou, D., \& Winefield, A. H. (2013). Social Support Moderates the Impact of Demands on Burnout and Organizational Connectedness: A Two-Wave Study of Volunteer Firefighters. Journal of Occupational Health Psychology, 18, 9-15. https://doi.org/10.1037/a0030804

Jackson, S. A., \& Csikszentmihalyi, M. (1999). Flow in Sports. Champaign, IL: Human Kinetics. https://doi.org/10.1123/jsep.24.2.133

Jackson, S. A., \& Eklund, R. C. (2002). Assessing Flow in Physical Activity: The Flow State Scale-2 and Dispositional Flow Scale-2. Journal of Sport and Exercise Psychology, 24, 133-150.

Jackson, S. A., \& Eklund, R. C. (2004). The Flow Scales Manual. Morgantown, WV: Fitness Information Technology.

Katsavouni, F., Bebetsos, E., Malliou, P., \& Beneka, A. (2015). The Relationship between Burnout, PTSD Symptoms and Injuries in Firefighters. Occupational Medicine, 66, 32-37. https://doi.org/10.1093/occmed/kqv144

Kawabata, M., Mallett, C. J., \& Jackson, S. A. (2008). The Flow State Scale-2 and Dispositional Flow Scale-2: Examination of Factorial Validity and Reliability for Japanese Adults. Psychology of Sport and Exercise, 9, 465-485.

https://doi.org/10.1016/j.psychsport.2007.05.005

Lourel, M., Abdellaoui, S., Chevaleyre, S., Paltrier, M., \& Gana, K. (2008). Relationships between Psychological Job Demands, Job Control and Burnout among Firefighters. North American Journal of Psychology, 10, 489-496.

Luthans, F., Luthans, K. W., \& Luthans, B. C. (2004). Positive Psychological Capital: Beyond Human and Social Capital. Business Horizons, 47, 45-50.

https://doi.org/10.1016/j.bushor.2003.11.007

Maslach, C., Jackson, S. E., \& Leiter, M. P. (1996). Maslach Burnout Inventory. Palo Alto, CA: Consulting Psychologists Press.

Maslach, C., Schaufeli, W. B., \& Leiter, M. P. (2001). Job Burnout. Annual Review of Psychology, 52, 397-422. https://doi.org/10.1146/annurev.psych.52.1.397

Mitani, S., Fujita, M., Nakata, K., \& Shirakawa, T. (2006). Impact of Post-Traumatic Stress Disorder and Job-Related Stress on Burnout: A Study of Fire Service Workers. Journal of Emergency Medicine, 31, 7-11. https://doi.org/10.1016/j.jemermed.2005.08.008

Moneta, G. B. (2012). On the Measurement and Conceptualization of Flow. In S. Engeser, (Ed.), Advances in Flow Research (pp. 23-50). New York, NY: Springer. https://doi.org/10.1007/978-1-4614-2359-1_2

Moustaki, M., \& Stalikas, A. (2012). The Hope Scale (HS). In A. Stalikas, S. Triliva, \& P. Roussi (Eds.), Psychometric Instruments in Greece (2nd ed., p. 738). Athens: Pedio. 
Nakamura, J., \& Csikszentmihalyi, M. (2009). Flow Theory and Research. In C. R. Snyder, \& S. J. Lopez (Eds.), Oxford Handbook of Positive Psychology (pp. 195-206). Oxford, MS: Oxford University Press. https://doi.org/10.1093/oxfordhb/9780195187243.013.0018

Nakamura, J., \& Csikszentmihalyi, M. (2014). The Concept of Flow. In M. Csikszentmihalyi (Ed.), Flow and the Foundations of Positive Psychology (pp. 239-263). Dordrecht: Springer. https://doi.org/10.1007/978-94-017-9088-8_16

Peterson, S. J., \& Byron, K. (2008). Exploring the Role of Hope in Job Performance: Results from Four Studies. Journal of Organizational Behavior, 29, 785-803. https://doi.org/10.1002/job.492

Riolli, L., \& Savicki, V. (2012). Firefighters' Psychological and Physical Outcomes after Exposure to Traumatic Stress: The Moderating Roles of Hope and Personality. Traumatology, 18, 7-15. https://doi.org/10.1177/1534765611435565

Sartori, R. D., \& DelleFave, A. (2014). First-Aid Activities and Well-Being: The Experience of Professional and Volunteer Rescuers. Journal of Social Service Research, 40, 242-254. https://doi.org/10.1080/01488376.2013.876954

Smith, T. D., DeJoy, D. M., Dyal, M. A., \& Huang, G. (2017). Impact of Work Pressure, Work Stress and Work-Family Conflict on Firefighter Burnout. Archives of Environmental \& Occupational Health, 1-8. https://doi.org/10.1080/19338244.2017.1395789

Smith, T. D., Hughes, K., DeJoy, D. M., \& Dyal, M. A. (2018). Assessment of Relationships between Work Stress, Work-Family Conflict, Burnout and Firefighter Safety Behavior Outcomes. Safety Science, 103, 287-292.

https://doi.org/10.1016/j.ssci.2017.12.005

Snyder, C. R. (1994). Hope and Optimism. Encyclopedia of Human Behavior, 2, 535-542.

Snyder, C. R. (2002). Hope Theory: Rainbows in the Mind. Psychological Inquiry, 13, 249-275. https://doi.org/10.1207/S15327965PLI1304_01

Snyder, C. R., Harris, C., Anderson, J. R., Holleran, S. A., Irving, L. M., Sigmon, S. T., Harney, P., et al. (1991). The Will and the Ways: Development and Validation of an Individual-Differences Measure of Hope. Journal of Personality and Social Psychology, 60, 570-585. https://doi.org/10.1037/0022-3514.60.4.570

Snyder, C. R., Rand, D. L., \& Sigmon, D. R. (2002). Hope Theory: A Member of the Positive Psychology Family. In C. R. Snyder, \& S. J. Lopez (Eds.), Handbook of Positive Psychology (pp. 74-88). London: Oxford University Press.

Steffen, L. E., \& Smith, B. W. (2013). The Influence of between and Within-Person Hope among Emergency Responders on Daily Affect in a Stress and Coping Model. Journal of Research in Personality, 47, 738-747. https://doi.org/10.1016/j.jrp.2013.06.008

Tuckey, M. R., \& Hayward, R. (2011). Global and Occupation-Specific Emotional Resources as Buffers against the Emotional Demands of Fire-Fighting. Applied Psycholo$g y$, 60, 1-23. https://doi.org/10.1111/j.1464-0597.2010.00424.x

Wan, C. S., \& Chiou, W. B. (2006). Psychological Motives and Online Games Addiction: A Test of Flow Theory and Humanistic Needs Theory for Taiwanese Adolescents. $C y$ ber Psychology \& Behavior, 9, 317-324. https://doi.org/10.1089/cpb.2006.9.317

Wang, C. J., Liu, W. C., \& Khoo, A. (2009). The Psychometric Properties of Dispositional Flow Scale-2 in Internet Gaming. Current Psychology, 28, 194-201. https://doi.org/10.1007/s12144-009-9058-x

Yotsidi, V., Pagoulatou, A., Kyriazos, T., \& Stalikas, A. (2018). The Role of Hope in Academic and Work Environments: An Integrative Literature Review. Psychology, 9, 385-402. https://doi.org/10.4236/psych.2018.93024 